\title{
COLORADOSCHOOLOFMINES
}

EARTH•ENERGY•ENVIRONMENT

Division OF ECONOMICS AND BUSINESS

WORKING PAPER SERIES

\section{Optimal environmental border adjustments under the General Agreement on Tariffs and Trade}

Edward J. Balistreri

Daniel T. Kaffine

Hidemichi Yonezawa

\author{
Working Paper 2014-03 \\ http: //econbus.mines . edu/working-papers/wp201403.pdf \\ Colorado School of Mines \\ Division of Economics and Business \\ 1500 Illinois Street \\ Golden, CO 80401
}

February 2014

(c) 2014 by the listed authors. All rights reserved. 
Colorado School of Mines

Division of Economics and Business

Working Paper No. 2014-03

February 2014

Title:

Optimal environmental border adjustments under the General Agreement on Tariffs and Trade*

Author(s):

Edward J. Balistreri

Division of Economics and Business

Colorado School of Mines

Golden, CO 80401-1887

ebalistr@mines.edu

Daniel T. Kaffine

Department of Economics

University of Colorado, at Boulder

Hidemichi Yonezawa

Institute of the Environment

University of Ottawa

\begin{abstract}
We consider the legal and economic context for border adjustments that might be used to augment subglobal carbon abatement. Following Markusen (1975) we establish optimal border policy in the presence of crossborder environmental damages. The optimal border policy includes a strategic component that is inconsistent with legal commitments under the General Agreement on Tariffs and Trade (GATT). Incorporating GATT compliance into the theory indicates an optimal border adjustment that taxes the carbon content of trade below the domestic carbon price. This theoretic finding is in contrast to the standard advice to impose the domestic carbon price on the carbon content of trade. The wedge between the domestic carbon price and the optimal environmental border adjustment occurs in general equilibrium because border adjustments inadvertently drive up consumption of emissions intensive goods in unregulated regions. We conclude our analysis with numeric simulations of Annex-I carbon policy. We find an optimal import tariff on the carbon content of aluminum that is on the order of $50 \%$ of the domestic carbon price. Countries that impose border carbon adjustments at the domestic carbon price will be extracting rents from unregulated regions at the expense of efficient environmental policy and consistency with international law.
\end{abstract}

JEL classifications: F18, Q54, Q40, K33

Keywords: climate policy, border tax adjustments, carbon leakage, trade and carbon taxes.

\footnotetext{
${ }^{*}$ Corresponding author: Division of Economics and Business, Colorado School of Mines, Golden, CO 80401-1887; email: ebalistr@mines.edu. A portion of this research was completed while the authors were supported through a generous donation to the Colorado School of Mines by the Alcoa Foundation.
} 


\section{Introduction}

An important challenge for economists and policymakers alike is that countries may coordinate on some issues while disagreeing on others. International law under the World Trade Organization (WTO) is designed to favor a cooperative trade outcome, where countries are punished if they attempt to use trade restrictions to extract rents from trade partners. At the same time, however, there is considerable disagreement over global climate policy. Coordinated efforts to mitigate climate change can reduce the global cost of action, but countries have failed to agree on either the absolute level of action or the distribution of burdens. If a subset of countries engages in climate policy, they may consider trade restrictions designed to mitigate a reshuffling of emissions to non-regulated regions (carbon leakage). For example, as noted in Cosbey et al. (2012), the U.S. considered trade restrictions within climate legislation in 2009, and France also considered trade restrictions in the context of phase III of the EU Emissions Trading System. These trade restrictions must, however, be consistent with the commitments to cooperative trade.

We modify the established theory on cross-border externalities to establish optimal environmental trade distortions in the context of cooperative trade. In doing so, we find an important general-equilibrium effect that indicates a divergence between the optimal domestic carbon price and optimal pricing of carbon embodied in trade. The border adjustment will not equal the domestic Pigouvian rate, even when the country's border adjustments are motivated purely by environmental concerns. The intuition is clear. While a carbon-based border tax sends a price signal that discourages foreign emissions it also encourages foreign consumption of the more carbon intensive goods. The theory indicates that Pigouvian based border adjustments are likely to be too aggressive. ${ }^{1}$ Our empirical simulations support this

\footnotetext{
${ }^{1}$ If there are extreme differences in carbon intensities across countries then this result can be reversed. That is, if the relative emissions intensity in the foreign country is extremely high, this may be enough to offset the general-equilibrium consumption effect (see Proposition 2 below).
} 
finding. The optimal import tax on the carbon content of aluminum is found to be $50 \%$ below the optimally set domestic carbon price.

The current set of Pigouvian-based border-adjustments being considered in the policy arena are sub-optimal from an environmental perspective. Because they are too aggressive, these adjustments also fall outside of the environmental provisions granted in the WTO's General Agreement on Tariffs and Trade (GATT). Pigouvian-based border-adjustments are in jeopardy of being challenged on the grounds that they are, at least in part, de facto a beggar-thy-neighbor policy. We focus on the theory of optimal border carbon adjustments to inform consistent policy advice. The key is to refine the established theory by incorporating GATT consistency using the transparent constraint proposed by Böhringer et al. (2014), which effectively eliminates any beggar-thy-neighbor incentives.

The literature on carbon based tariffs focuses on two key theoretic papers. First, Markusen (1975) establishes the optimal unilateral domestic and trade instruments under a crossborder production externality. Markusen illustrates the theory in a transparent two-good two-country neoclassical general equilibrium. Markusen completes his analysis by considering a series of second-best responses. Markusen's results are important on a number of fronts including establishing the strategic and environmental components of optimal trade policy. Markusen also clearly highlights the role of relative international prices (the terms of trade) as a mechanism to signal foreign agents. A small country has neither a strategic nor an environmental incentive to distort trade because a lack of market power indicates an inability to affect foreign-agent behavior. Markusen's analysis is not specifically focused on carbon tariffs, but it is an essential starting point for any analysis of cross-border externalities.

The second key theoretic contribution is by Hoel (1996) who looks at carbon taxes under less than global cooperation. Hoel finds that carbon taxes should be equalized across sectors in the home (regulated) region as long as carbon tariffs are available for the traded goods. Hoel's analysis achieves a set of conclusions on the first and second-best policy responses 
consistent with Markusen (1975) in the more general context of a model with any number of goods which may, or may not, be tradable. Hoel's approach is slightly different than Markusen's, however, in that foreign carbon emissions are simply modeled as a function of net imports. The logic is clear that home-country imports change world prices and these world prices subsequently affect foreign emissions. We would emphasize the full chain, which includes the role of carbon tariffs in sending a price signal to foreign agents. ${ }^{2}$ The theory established by Hoel is the foundation for much of the contemporary work on climate policy and carbon tariffs.

While both Hoel (1996) and Markusen (1975) establish an optimal tariff which includes a strategic and additive environmental term, the environmental term is inherently entwined with terms-of-trade adjustments. It is not clear, at least from our perspective, that the form of the environmental term will be preserved once we incorporate GATT consistency. We derive the environmental term under GATT consistency and do show it to be consistent with the original theory. We contribute to the theoretic literature by clearly decoupling the strategic versus environmental incentives to distort trade.

For the analysis in this paper we return to the earlier theory established by Markusen (1975). Markusen's treatment is less general than that of Hoel (1996), in terms of commodity dimensionality, but it is more transparent and explicitly represents the foreign economy in general equilibrium. For our purpose extending Markusen's theory more clearly develops the intuition behind our results establishing the separable environmental incentive to distort trade. This context helps us establish the quantitative value of the trade distortion, relative to the Pigouvian tax. Using Markusen's model we reveal the offsetting impact that carbon tariffs have through encouraging foreign consumption of carbon intensive goods, and this

\footnotetext{
${ }^{2}$ Hoel (1996) argues (on page 25) that countries with little market power might still have significant carbon tariffs. His theory (consistent with Markusen (1975)) shows, however, that the optimal tariff must approach zero as international market power approaches zero. The distortion cannot be beneficial unless it changes foreign behavior.
} 
favors less distortionary tariffs.

With the theory established by Markusen (1975) and Hoel (1996) it is surprising how pervasive the advice is to establish the border tariff by applying the domestic carbon price to embodied emissions, or equivalently requiring forfeiture of an emissions permit upon importing embodied carbon. Examples of such advice include Stiglitz (2013), Cosbey et al. (2012), Aldy and Stavins (2008), and Barrett and Stavins (2003). Some authors consider such border policies as sanctions against non-participating countries [e.g., Böhringer et al. (2013b) and Aldy et al. (2001)]. There are two exceptions that reflect the theoretic result that the optimal environmental border adjustment is below domestic carbon pricing: our earlier work (Yonezawa et al., 2012); and the recent paper by Böhringer et al. (2013a). In Böhringer et al. (2013a) they run a set of scenarios in their Computable General Equilibrium model that approximate the optimal border adjustments. These are approximations because they use a set of reference scenarios to establish trade responses and do not explicitly include a valuation for the environment (which is endogenous to abatement). Our contribution is to clearly establish the theory for border adjustments free of strategic incentives and to demonstrate their operation in a general equilibrium that includes environmental valuation in establishing the optimal adjustment.

We proceed with the paper as follows: Section 2 sets the legal context for border adjustments. We argue that border carbon adjustments can be GATT compatible if the sole objective is environmental. Section 3 presents the economic theory of optimal border policy, in which we disentangle the strategic and environmental objectives. Section 4 presents a set of data driven numeric simulations that show the significance of our argument to set the embodied carbon adjustment below the domestic carbon price. Section 5 concludes. 


\section{Legal context}

For at least the last decade, legal and economic scholars have considered the prospects of using border policy to augment subglobal climate action. There is an obvious tension between environmentally motivated border policies and the WTO's objective of cooperative trade. While there have been attempts to reconcile carbon based tariffs as a tax adjustment under Articles II and III of the GATT (and Article XVI for carbon based export rebates), as reviewed below, the general view is that carbon-based border policies would most easily be legitimized under the General Exceptions offered under Article XX. The text of Article $\mathrm{XX}$ is reproduced in Appendix A. In particular, a case can be made that border carbon adjustments are policy measures covered under either paragraph (b): " necessary to protect human, animal or plant life or health," or paragraph (g): "relating to the conservation of exhaustible natural resources if such measures are made effective in conjunction with restrictions on domestic production or consumption." While Article XX offers an opportunity to utilize border carbon adjustments as a compliment to subglobal action, its preamble clearly sets some limits. The policy measures cannot be "applied in a manner which would constitute a means of arbitrary or unjustifiable discrimination between countries" and cannot be a "disguised restriction on international trade." In this context we argue that carbon adjustments should be limited to environmental objectives.

There are several good reviews of legal issues related to border carbon adjustments. Tamiotti (2011), Pauwelyn (2013) and Horn and Mavroidis (2011) cover legal issues for carbon regulation in the US and/or Europe in general. van Asselt et al. (2009) focuses on the US Climate Security Act (Liberman-Warner bill), whereas de Cendra (2006) focuses on the EU ETS. A recent comprehensive look at the prospects for border adjustments is offered by Cosbey et al. (2012). In this report the authors consider a general set of rules for guiding the design of border adjustments. The literature focuses on some central questions. First, 
is carbon regulation eligible for border tax adjustments? Second, are imported products treated less favorably than "like" domestic products? Third, does discrimination between like imported products from different countries occur because of the country of origin? Fourth, if border carbon adjustments are not compatible with WTO rules, can we consider the adjustments an exception?

Border carbon adjustments might be thought of as a type of border tax adjustment, in the same sense that other indirect taxes are adjusted to account for differences in international treatment. Under this interpretation, border adjustments may be useful in extending the reach of domestic policy by filling the gap between domestic taxes and foreign taxes. GATT Article II.2(a) allows WTO members to impose border tax adjustments as "a charge equivalent to an internal tax ... in respect of the like domestic product". GATT Article III.2 also states that foreign products shall not be subject "to internal taxes or other internal charge of any kind in excess of those applied, directly or indirectly, to like domestic products." Border tax adjustments are permitted as long as they are not in excess of internal domestic taxes. In the simplest example, a sales tax on a foreign automobile is permitted to the extent that this sales tax does not exceed the sales tax applied to a "like" domestic automobile. While the sales tax on the foreign automobile is not technically collected at the border, this is defined as a border tax adjustment under international law, because it brings the tax treatment of the imported good up to the domestic level under what is termed the "destination principle" (see GATT (1970)).

Both GATT Article II.2(a) and GATT Article III.2 limit the use of border tax adjustments to "products." Taxes on products (indirect taxes) are eligible for tax adjustments, whereas taxes on factors (direct taxes) are not. The question is whether a carbon tax is an indirect tax or not, and this interpretation could be contingent on the actual administration of the domestic carbon policy. For example, a crude oil well-head carbon tax could be viewed differently than a carbon tax on gasoline, even if they have (conceptually) the same economic 
implications.

Another issue related to GATT Article II.2(a) is how to interpret "in respect of an article from which the imported product has been manufactured or produced in whole or in part." The question is whether inputs have to be physically incorporated into the final product. Article II.2(a) may not permit the application of Article II to energy inputs or fossil fuels used in production. In the 1987 GATT Superfund case, however, the GATT panel found that US taxes on certain imported chemicals were consistent border tax adjustments, because these chemicals were manufactured using feedstocks subject to a US environmental tax. This is cited as an opportunity to justify border carbon adjustments under the same logic.

The legal administration of the carbon policy is also of critical legal importance. Although economists tend to think that carbon taxes and cap-and-trade schemes are similar (in theory they can be equivalent), WTO rules are likely to see them differently. Pauwelyn (2013) points out that a cap-and-trade scheme may not be eligible for border tax adjustment, even if a largely equivalent carbon tax is eligible. As de Cendra (2006) points out, the permit allocation mechanism matters. In general, tax adjustments must be an adjustment for a tax, which entails a payment to the government. Emissions permits that are freely allocated do not directly impact government revenues, and therefore fall outside the definition of a tax. Auctioned permit schemes do generate revenues and could more easily fit, legally, under the border tax adjustment provisions.

The key challenge faced by border carbon adjustment as justified under the border tax adjustment provision is that they will be discriminatory. The national treatment principle (GATT Article III) requires that imported products should not be discriminated against when compared to "like" domestic products. The most-favoured nation treatment principle (GATT Article I) requires that "like" imported products from different countries should not be discriminated against because of the country of origin. But, what are like products? Some products are considered identical as final products, although the production methods 
are different. Accordingly, the energy consumption and embodied carbon can be different for what are traditionally considered "like" products. Given that carbon (or carbon emissions) is the physical measure of the tax base and embodied carbon is the basis of border adjustments, it is hard to imagine that the adjustments would meet the non-discriminatory requirements.

It would seem, therefore, that Article XX would need to be used to legitimize any WTO compliant border carbon adjustments. Once the border carbon adjustments are adopted under at least one of the exceptions outlined in Article XX, policy must satisfy the requirements in the preamble. In other words, the border carbon adjustments must pursue the environmental objective. In the following section we modify the theory on optimal tariffs under cross-border externalities to isolate the environmental objective. Our prescription is a border adjustment that prices embodied carbon below the domestic carbon price. This contrasts with the policy guidance offered by economists to date. ${ }^{3}$ For example, Cosbey et al. (2012) explicitly advice that the pricing of carbon content should be based on the carbon price in the abating country and Stiglitz (2013) proposes a carbon-added tax where producers from unregulated countries would have to produce a receipt that the carbon tax was paid, or pay the difference, in order to sell in regulated countries. We show below that such advice will result in an over taxation of trade, rent extraction from unregulated countries, and thus a violation of Article XX.

\section{Theory}

In this section we first present the Markusen (1975) theory, indicating the additive nature of the environmental and strategic (rent seeking) components of a country's optimal tariff. We then introduce a constraint representing the GATT commitment, which effectively eliminates the strategic term. This framework allows us to analyze national incentives to distort trade

\footnotetext{
${ }^{3}$ The noted exceptions are Yonezawa et al. (2012) and Böhringer et al. (2013a).
} 
for purely environmental objectives. We derive a simple closed-form relationship between the optimal environmental tariff and the optimal domestic (Pigouvian) production tax. We build directly on Markusen (1975), but our theory would extend to the multi-commodity environment explored by Hoel (1996). The key insights provided here include a theoretic foundation for the separability of the environmental and strategic components of commercial policy and the divergence of optimal domestic environmental taxes and the optimal border adjustment.

Consider a simple two-good two-country model. Both countries, country $N$ and country $S$, produce and trade the goods $X$ and $Y$, and pollution is a function of the domestic and foreign production of good $X$. The pollution level, $Z$, is represented as follows:

$$
Z=Z\left(X_{N}, X_{S}\right)
$$

The efficient transformation function that determines a country's output of $X$ and $Y$ is given by:

$$
F_{r}\left(X_{r}, Y_{r}\right)=0 \quad \text { or } \quad Y_{r}=L_{r}\left(X_{r}\right), \quad r \in\{N, S\}
$$

where $L_{r}\left(X_{r}\right)$ maps out the efficient frontier (PPF) in terms of $Y_{r}$ as a function of $X_{r}$. Letting $C_{i N}$ represent the consumption of good $i$ in country $N$, the welfare of the North is

$$
U_{N}=U_{N}\left(C_{X N}, C_{Y N}, Z\right)
$$

We use $Y$ as a numeraire so that all prices are ratios in terms of $Y$. Let $q, p$, and $p^{*}$ denote the price ratio faced by consumers in the North, the price ratio faced by producers in the North, and world price ratio faced by consumers and producers in the South. The policy instruments considered are $\tau$, a tariff rate set by the North, and $t_{X}$, as the production tax 
rate in the North. Assuming no other distortions, the price relationships are

$$
\frac{p}{1-t_{X}}=\frac{p^{*}}{1-\tau}=q
$$

The taxes are based on the consumer price. The balance-of-payments constraint for the North is given by

$$
p^{*} e_{X}+e_{Y}=0, \quad e_{X}=X_{N}-C_{X N}, \quad e_{Y}=Y_{N}-C_{Y N},
$$

where $e_{i}$ is the North's net export of good $i$. We are primarily interested in the case where the North imports the polluting good $\left(e_{X}<0\right)$ to inform current climate policy debates. The theory, however, generalizes to either trade pattern. ${ }^{4}$

As in Markusen (1975), we first consider the case where both environmental policy and trade policy are noncooperative. Given the above, the North sets its tariff $\tau$ and production tax $t_{X}$ unilaterally to maximize (3), yielding the following:

Theorem 1. (Markusen, 1975). The optimal unilateral tariff and production tax in a noncooperative trade setting are given by:

$$
\begin{aligned}
\tau & =e_{X} \frac{\partial U_{N} / \partial C_{Y N}}{\partial U_{N} / \partial C_{X N}} \frac{d p^{*}}{d e_{X}}-\frac{\partial U_{N} / \partial Z}{\partial U_{N} / \partial C_{X N}} \frac{\partial Z}{\partial X_{S}} \frac{d X_{S}}{d p^{*}}\left(-\frac{d p^{*}}{d e_{X}}\right), \\
t_{X} & =-\frac{\partial U_{N} / \partial Z}{\partial U_{N} / \partial C_{X N}} \frac{\partial Z}{\partial X_{N}} .
\end{aligned}
$$

Proof. See Appendix B

The optimal import tariff consists of the (non-environmental) strategic component as the first term and the environmental component as the second term. The optimal production tax

\footnotetext{
${ }^{4}$ In the case that $e_{X}>0$, where the North exports the polluting good, $\tau$ is interpreted as the North's export subsidy (or equivalently $-\tau$ is the export tax). Thus, the general pricing equation (4) is preserved in any case.
} 
is the Pigouvian rate because $-\frac{\partial U_{N} / \partial Z}{\partial U_{N} / \partial C_{X N}} \frac{\partial Z}{\partial X_{N}}$ is the marginal environmental damage from a unit of domestic production. ${ }^{5}$ Notice that in the absence of an environmental externality, $\frac{\partial Z}{\partial X_{N}}=\frac{\partial Z}{\partial X_{S}}=0$, the standard neo-classical result is obtained, where the domestic production tax is zero and the trade distortion is purely a strategic optimal tariff $\left(\tau=e_{X} \frac{\partial U_{N} / \partial C_{Y N}}{\partial U_{N} / \partial C_{X N}} \frac{d p^{*}}{d e_{X}}\right)$.

While the above constitutes optimal policy in an noncooperative trade setting, the first component of the optimal tariff (the strategic term) is in violation of GATT, as it exploits the terms-of-trade to extract rents from the South. As such, we next determine the optimal policy in a cooperative trade setting, where such beggar-thy-neighbor strategic tariffs are not allowed. We thus modify the Markusen model by adding an endogenous lump-sum transfer that eliminates this strategic incentive to distort trade, per Böhringer et al. (2014). ${ }^{6}$ The transfer payment $T$ is determined such that the South is not made worse off by trade policy implemented in the North. Let $\bar{U}_{S}$ be the measure of welfare in the South in the absence of tariffs and let $U_{S}=U_{S}\left(C_{X S}, C_{Y S}\right)$ equal the South's realized welfare. ${ }^{7}$ A complementary slack condition is indicated that ensures GATT consistency of added trade distortions; where $U_{S}-\bar{U}_{S} \geq 0$ and $T \geq 0$, and $T\left(U_{S}-\bar{U}_{S}\right)=0$. Under a set of border adjustments imposed by the North there is downward pressure on $U_{S}$ and we can be sure that the following holds:

$$
U_{S}=\bar{U}_{S} ; \quad T>0
$$

The balance-of-payments equation, (5), is modified as follows when we include the transfer, $T:$

$$
p^{*} e_{X}+e_{Y}=T
$$

\footnotetext{
${ }^{5}$ The term $\frac{\partial U_{N} / \partial Z}{\partial U_{N} / \partial C_{X N}}$ is negative because the pollution level $Z$ has a negative impact on welfare.

${ }^{6}$ There are alternative ways to represent the constraints imposed by cooperative trade agreements, such as the potential for retaliatory tariffs. Our formulation of the endogenous lump-sum transfer, however, captures the purest (transparent) instrument which perfectly neutralizes the strategic trade incentives. Distortional retaliation available under WTO rules would have additional general equilibrium effects and therefore are not considered.

${ }^{7}$ Note that we assume no environmental valuation in the South for simplicity.
} 
We now consider the optimal policy as chosen in the North when environmental policy is noncooperative, but trade policy is subject to cooperative trade agreements. Given these modifications, the North sets its tariff $\tau$ and production tax $t_{X}$ unilaterally as before, but accounting for the fact that losses in the South's welfare require compensation via the endogenous transfer:

Proposition 1. The optimal unilateral tariff and production tax in a cooperative trade setting are given by:

$$
\begin{aligned}
\tau & =-\frac{\partial U_{N} / \partial Z}{\partial U_{N} / \partial C_{X N}} \frac{\partial Z}{\partial X_{S}} \frac{d X_{S}}{d p^{*}}\left(-\frac{d p^{*}}{d e_{X}}\right), \\
t_{X} & =-\frac{\partial U_{N} / \partial Z}{\partial U_{N} / \partial C_{X N}} \frac{\partial Z}{\partial X_{N}} .
\end{aligned}
$$

Proof. See Appendix C

Comparing Proposition 1 with Theorem 1, the addition of the transfer has effectively eliminated the strategic component in the optimal tariff in a cooperative trade setting. While this isolates the environmental component of the optimal tariff, nonetheless it is clear that the optimal tariff is not simply equal to the Pigouvian rate and critically depends on the North's ability to affect international prices with its tariff. That is, if $d p^{*} / d e_{X}=0$ the optimal environmental tariff is zero. A small country cannot send a price signal to foreign agents through a tariff and optimally chooses free trade.

We next consider how the optimal tariff derived above compares with the production tax rate, which is optimally set at the Pigouvian rate. Let $\theta_{N} \equiv-\frac{\partial U_{N} / \partial Z}{\partial U_{N} / \partial C_{X N}} \frac{\partial Z}{\partial X_{N}}$ represent the Pigouvian rate (marginal external damage) for production in the North, and $\theta_{S} \equiv$ $-\frac{\partial U_{N} / \partial Z}{\partial U_{N} / \partial C_{X N}} \frac{\partial Z}{\partial X_{S}}$ represent the Pigouvian rate for production in the South. If it were allowed, $\theta_{S}$ is the rate at which the North would like to directly regulate production in the South.

Proposition 2. In a cooperative trade setting, the optimal tariff $\tau$ is: 
i) less than the Pigouvian rate for production in the South, such that $\tau<\theta_{S}$;

ii) less than the production tax rate in the North, $\tau<t_{X}$, if $\frac{\partial Z}{\partial X_{N}}=\frac{\partial Z}{\partial X_{S}}$;

iii) greater than the production tax rate in the North $\tau>t_{X}$, only if $\frac{\partial Z / \partial X_{N}}{\partial Z / \partial X_{S}}<\frac{d X_{S}}{d p^{*}} \frac{d p^{*}}{d\left(-e_{X}\right)}$.

Proof. i) From (9) the optimal tariff is

$$
\tau=\theta_{S} \frac{d X_{S}}{d p^{*}} \frac{d p^{*}}{d\left(-e_{X}\right)}
$$

where $-e_{X}$ is the North imports of good $X$. In order to prove that the optimal tariff is less than the Pigouvian rate, we derive the following equation from the supply and demand relationship (analogous to (5)) in the South $\left(X_{S}=C_{S X}+\left(-e_{X}\right)\right)$ :

$$
\frac{d X_{S}}{d p^{*}} \frac{d p^{*}}{d\left(-e_{X}\right)}=\frac{d C_{S X}}{d p^{*}} \frac{d p^{*}}{d\left(-e_{X}\right)}+\frac{d\left(-e_{X}\right)}{d p^{*}} \frac{d p^{*}}{d\left(-e_{X}\right)}
$$

The left-hand term is clearly positive (given convexity of the production set) and the fact that $\frac{d p^{*}}{d\left(-e_{X}\right)}$ is positive. ${ }^{8}$ The last term on the right-hand side is equal to unity, and the term $\frac{d C_{S X}}{d p^{*}}$ is negative (given convexity of the consumer's upper-level set). Taken together signing the elements of (11) gives

$$
\frac{d X_{S}}{d p^{*}} \frac{d p^{*}}{d\left(-e_{X}\right)}<1
$$

Thus, $\tau<\theta_{S}$.

ii) From $(9), t_{X}=\theta_{N}$. If the environmental damage associated with producing the good $X$ is the same in the North and the South $\left(\partial Z / \partial X_{N}=\partial Z / \partial X_{S}\right)$, then $\theta_{S}=\theta_{N}$ and thus $\tau<t_{X}=\theta_{N}=\theta_{S}$ per $i$ ) above.

iii) Follows from direct comparison of $\tau$ and $t_{X}$ in (9).

To understand the first result, note that although the Pigouvian rate $\theta_{S}$ reflects the marginal environmental damage of production in the South, it is adjusted in the optimal

\footnotetext{
${ }^{8} \mathrm{An}$ increase in North imports $\left(-e_{X}\right)$ drives up the international price $\left(p^{*}\right)$.
} 
tariff by two terms: (1) the ability of the North to influence prices in the South through changing import volumes $\left(\frac{d p^{*}}{d\left(-e_{X}\right)}\right)$, and $(2)$ the impact of that price change on production in the South $\left(\frac{d X_{S}}{d p^{*}}\right)$. The tariff decreases the price faced by producers in the South, and production of $X$ is discouraged in the South. The lower price also encourages consumption of $X$ in the South. Thus, the decrease in environmental damage from decreased imports is partially offset by the increase in consumption in the South. Intuitively, $\tau$ is an imperfect instrument for influencing production in the South because the price change is limited by the negative $\frac{d C_{S X}}{d p^{*}}$ term. This is the unintended consumption effect of the environmental tariff. Consumption of the polluting good is encouraged in the South making the optimal tariff less than the Pigouvian rate that the North would like to impose on production in the South.

The second result shows that if the environmental damage associated with producing $\operatorname{good} X$ is the same between the North and the South $\left(\partial Z / \partial X_{N}=\partial Z / \partial X_{S}\right)$, then the optimal tariff is always less than the optimal production tax. It is possible, however, that the marginal environmental damage per unit of production may be higher in the South. Nonetheless, the third result shows that in order for the tariff to exceed the production tax rate, a large difference in marginal damages from production is required to offset the general equilibrium effect on the South's consumption response. For example, if $\frac{d X_{S}}{d p^{*}} \frac{d p^{*}}{d\left(-e_{X}\right)}=0.5$, such that a one unit decrease in imports leads to a 0.5 unit decrease in production in the South, then the marginal damage from production in the South would need to be more than double that in the North for $\tau>t_{X}$. Taken together, the above results indicate that it is unlikely to be optimal to set the tariff equal to the Pigouvian production tax.

Empirically, equation (10) provides some insight into determining which commodities potentially have large differences between optimal and Pigouvian tariff rates. If $\frac{d p^{*}}{d\left(-e_{X}\right)}$ is small, the optimal tariff becomes small and the gap with the Pigouvian rate becomes large. In other words, if changes in imports do not affect world prices significantly the price signal to foreign agents is weak, and the optimal tariff is close to zero. The amount of imports 
relative to world production (import share) can indicate whether $\frac{d p^{*}}{d\left(-e_{X}\right)}$ is small or large. For example, if the imports are a small share of the world market, it is likely that changing the import amount will not substantially affect world prices.

Also from (10) we see that if $\frac{d X_{S}}{d p^{*}}$ is small the optimal tariff becomes small. In this case, if the world price change does not affect production in non-regulated regions significantly, the optimal tariff is close to zero. The key responses come from both the consumption and the production sides of the foreign economy. In the case that consumers in the South are very responsive to price (high elasticities of substitution) the more negative is $\frac{d C_{S X}}{d p^{*}}$, the smaller is the optimal tariff. On the production side, if production is relatively insensitive to the price changes (low elasticities of transformation) the smaller is the optimal tariff.

In our final extension of the Markusen (1975) theory we consider taxes on pollution and embodied pollution. In the previous discussion optimal policies are derived in terms of a tax or tariff on production $(X)$, while border adjustment policies under consideration are typically framed as a tax or tariff on pollution $(Z)$. To explore this nuance, suppose the tax and tariff is levied on pollution, such that the price relationships in equation (4) are now:

$$
\frac{p}{1-t_{X} \frac{\partial Z}{\partial X_{N}}}=\frac{p^{*}}{1-\tau \frac{\partial Z}{\partial X_{S}}}=q
$$

Let $\gamma=-\frac{\partial U_{N} / \partial Z}{\partial U_{N} / \partial C_{X N}}$ represent the Pigouvian rate (now on pollution), which reflects the marginal external damage of a unit of pollution $Z$.

Proposition 3. When the tax and tariff are levied on pollution $Z$,

i) The optimal unilateral tariff and production tax in a noncooperative trade setting are given by:

$$
\begin{aligned}
\tau & =\frac{e_{X}}{\partial Z / \partial X_{S}} \frac{\partial U_{N} / \partial C_{Y N}}{\partial U_{N} / \partial C_{X N}} \frac{d p^{*}}{d e_{X}}-\frac{\partial U_{N} / \partial Z}{\partial U_{N} / \partial C_{X N}} \frac{d X_{S}}{d p^{*}}\left(-\frac{d p^{*}}{d e_{X}}\right), \\
t_{X} & =-\frac{\partial U_{N} / \partial Z}{\partial U_{N} / \partial C_{X N}} .
\end{aligned}
$$


ii) The optimal unilateral tariff and production tax in a cooperative trade setting are given by:

$$
\begin{aligned}
\tau & =-\frac{\partial U_{N} / \partial Z}{\partial U_{N} / \partial C_{X N}} \frac{d X_{S}}{d p^{*}}\left(-\frac{d p^{*}}{d e_{X}}\right), \\
t_{X} & =-\frac{\partial U_{N} / \partial Z}{\partial U_{N} / \partial C_{X N}} .
\end{aligned}
$$

iii) The optimal tariff in a noncooperative setting is strictly less than the Pigouvian rate applied to pollution, $\tau<\gamma$.

Proof. The proof of i) and ii) follow from the proofs of Theorem 1 and Proposition 1 in Appendix B and C. The proof of iii) follows from the fact that $\tau=\gamma \frac{d X_{S}}{d p^{*}}\left(-\frac{d p^{*}}{d e_{X}}\right), t_{X}=\gamma$, and the proof of $i$ ) in Proposition 2.

The first result shows that although pollution is not explicitly traded, nonetheless the North's optimal tariff contains a strategic component in a noncooperative setting. However, turning to the cooperative setting with the transfer in place, the strategic component is once again eliminated in the second result. When the tariff and tax are placed on pollution, the tariff simplifies to $\tau=\gamma \frac{d X_{S}}{d p^{*}}\left(-\frac{d p^{*}}{d e_{X}}\right)$ and the production tax is simply the Pigouvian rate $t_{X}=\gamma$. Because the tariff again lowers world price and encourages consumption in the South, the optimal tariff rate levied on pollution is strictly less than the Pigouvian rate. As before, if changes in imports do not affect world prices significantly, or if the South's production of the polluting good is relatively unresponsive to changes in world price, the optimal tariff may be quite small. Taken together, these indicators of smaller optimal tariffs imply a larger gap between the optimal domestic carbon price and the optimal trade adjustments. In the following section we explore the size of this gap, and illustrate its significance in a model calibrated to data. 


\section{Optimal border adjustments on Aluminum}

In this section, we use a specific, data driven, illustration of the potential difference between the optimal domestic carbon price and the trade adjustment. The context for the illustration is Annex-I subglobal carbon abatement, where there is an option to impose border adjustments on aluminum trade. The aluminum sector is a good choice for the empirical analysis because of its dependence on fossil energy and trade intensity. ${ }^{9}$ These characteristics make aluminum trade a likely target of border carbon adjustments. Focusing on a single commodity also provides a relatively clean experimental setting for our illustration. More ambitious policies, such as imposing border carbon adjustments on all imports, will significantly influence carbon leakage and therefore the domestic marginal utility of abatement, which complicates our comparisons. ${ }^{10}$ In our relatively transparent numeric simulations, we find that the optimal border adjustments for the aluminum sector are lower than the domestic Pigouvian rate. The difference from the Pigouvian rate is $50 \%$ when we use only import tariffs, whereas the difference is $20 \%$ when we use both import tariffs and export subsidies on embodied carbon.

Our numeric model is a multi-commodity multi-region static general-equilibrium representation of the global economy with detailed carbon accounting. We adopt the structure and elasticities employed by Rutherford (2010) in his examination of carbon tariffs. We also follow Rutherford (2010) and Böhringer et al. (2013a) in calculating carbon embodied in

\footnotetext{
${ }^{9}$ As noted in Cosbey et al. (2012), primary aluminum is identified as an energy-intensive, trade-exposed industry. In addition, the analysis presented here was largely completed while the authors were supported through an Alcoa Foundation grant providing additional motivation to consider aluminum. The results also appear in Yonezawa's thesis [Yonezawa (2012), Chapter 4].

${ }^{10}$ To illustrate the theory, we impose a domestic carbon price that matches the money metric marginal utility of abatement. However, because border adjustments mitigate carbon leakage, the marginal utility of abatement is endogenous to the level of border adjustment. The domestic carbon price is relatively stable, however, given that we are only applying border adjustments on aluminum (which only marginally reduces leakage). The domestic carbon price varies only slightly between $\$ 35.26$ per ton $\mathrm{CO}_{2}$ with no border adjustments to $\$ 35.23$ per ton $\mathrm{CO}_{2}$ with a very large border adjustment of $\$ 70$ per ton applied to $\mathrm{CO}_{2}$ embodied in Annex-I aluminum imports. This range of border adjustments covers our illustrative experiments.
} 
trade using the multi-region input-output (MRIO) technique. For every trade flow, a carbon coefficient is calculated that includes the direct and indirect carbon content, as well as the carbon associated with transport.

We augment the Rutherford (2010) model in two important ways. First, in order to find optimal carbon pricing we must include an explicit representation of environmental valuation in preferences. We simply include a preference for the environment (disutility from global emissions) in the Annex-I CES expenditure system. Consistent with the theory presented above, we assume that environmental quality is separable from consumption with an elasticity of substitution between environmental quality and private consumption of $0.5 .^{11} \mathrm{We}$ calibrate the environmental preference to be roughly consistent with contemporary proposals on climate policy. With a 20\% cap on Annex-I carbon emissions (and no border adjustments) the model is used to compute a carbon price of $\$ 35.26$ per ton of $\mathrm{CO}_{2}$. With this information established, we recalibrate the Annex-I expenditure function such that this is the moneymetric marginal utility of (separable) emissions abatement. In the calibrated benchmark, therefore, the Annex-I region is pursuing optimal unilateral abatement with a $20 \%$ cap on $\mathrm{CO}_{2}$ emissions, conditional on no border adjustments. With border adjustments Annex-I can improve its welfare, because, on the margin, emissions reductions achieved through border adjustments are less costly than domestic abatement.

The second modification to the Rutherford (2010) model is to include the Böhringer et al. (2014) complementary slack condition, which under border adjustments is given by equation (7). This eliminates the strategic incentive that the Annex-I coalition has to extract rents from other regions. In this context carbon-based border adjustments are only used to achieve the environmental objective, per the preceding theory. ${ }^{12}$

\footnotetext{
${ }^{11}$ Non-separabilities could be important in the context of climate change as emphasized by Carbone and Smith (2013), but these are beyond the theory we illustrate.

${ }^{12}$ Yonezawa (2012) also shows this using our numeric model. Independent of environmental valuation, the Annex-I region has a large incentive to distort trade without the transfer. With the transfer activated the Annex-I region optimally chooses not to distort trade.
} 
Table 1: Scope of the Empirical Model

\begin{tabular}{|c|c|c|c|c|c|}
\hline \multicolumn{2}{|c|}{ Regions: } & \multicolumn{2}{|c|}{ Goods: } & \multicolumn{2}{|c|}{ Factors: } \\
\hline Annex-I & Annex I (except Russia) & OIL & Refined oil products & LAB & Labor \\
\hline MIC & Middle-High Income, n.e.c. & GAS & Natural Gas & CAP & Capital \\
\hline LIC & Low Income Countries, n.e.c. & ELE & Electricity & RES & Natural Resources \\
\hline & & COL & Coal & & \\
\hline & & CRU & Crude Oil & & \\
\hline & & ALU & Aluminum & & \\
\hline & & NFM & Non-ferrous metals & & \\
\hline & & EIT & Energy Intensive, n.e.c. & & \\
\hline & & TRN & Transportation & & \\
\hline & & $\mathrm{AOG}$ & All other goods & & \\
\hline
\end{tabular}

To calibrate the model we use GTAP 7.1 data (Narayanan and Walmsley, 2008), which represents global production and trade with 113 countries/regions, 57 commodities, and five factors of production. For our purpose, we aggregate the data into three regions, nine commodities that include non-ferrous metals, and three factors of production. We then split out the primary and secondary aluminum industry from the non-ferrous metals accounts using data from Allen (2010) and the United States Geological Survey report on aluminum: Bray (2010). ${ }^{13}$ Table 1 summarizes the aggregate regions, commodities, and factors of production represented in the model. Annex-I parties to the United Nations Framework Convention on Climate Change (UNFCCC) except Russia are aggregated as carbon-regulated regions. The rest of the world is divided into two aggregate regions according to World Bank income classifications.

In the first set of simulations we show that the Annex-I coalition has a relatively large incentive to impose tariffs on aluminum imports. If Annex-I countries are motivated by both strategic and environmental objectives, the optimal pricing of embodied carbon associated with imports is about $\$ 70$ per ton $\mathrm{CO}_{2}$ as illustrated in Figure 1. This is double the domestic carbon price. Translating the $\$ 70$ per ton embodied carbon price into an ad valorem tariff

\footnotetext{
${ }^{13} \mathrm{~A}$ full description of the augmentation to the GTAP data to include aluminum (and the computer code used) is offered in Yonezawa (2012).
} 


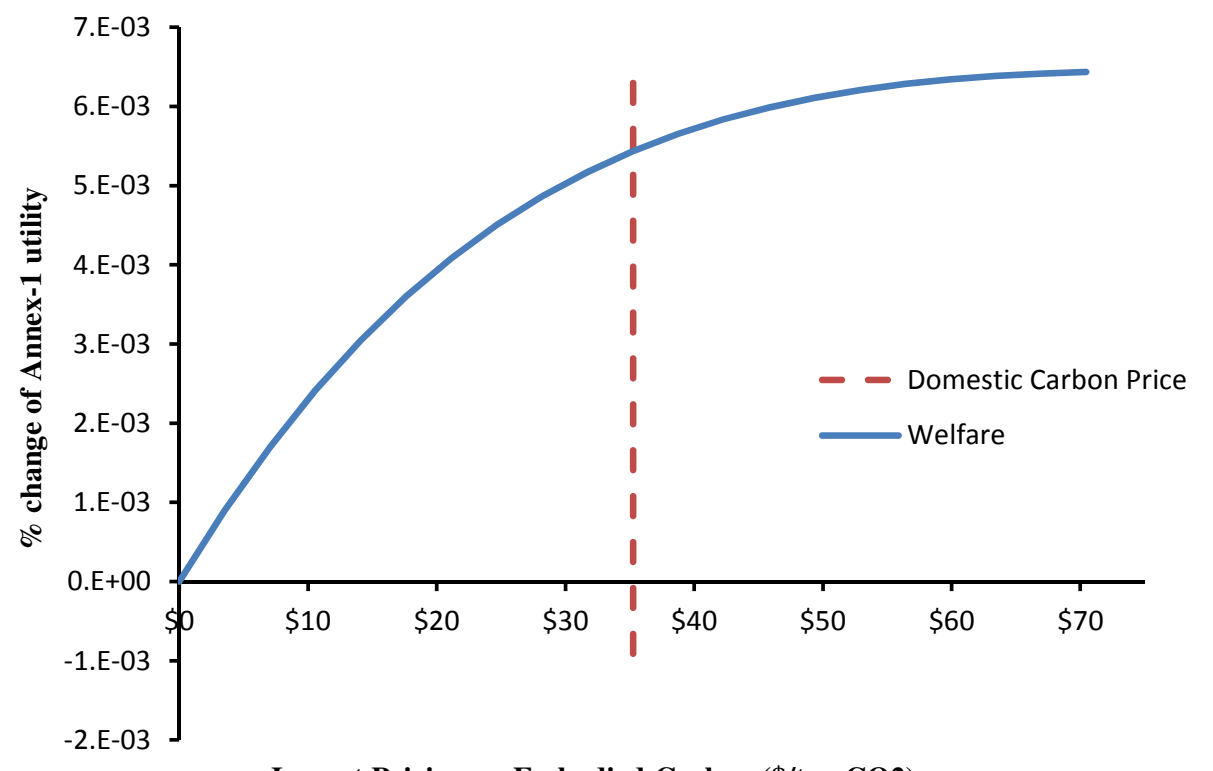

Import Pricing on Embodied Carbon (\$/ton CO2)

Figure 1: Aluminum Import Border Adjustment: Non-GATT Constrained

equivalent we get a $22 \%$ tariff on MIC aluminum imports and a $30 \%$ tariff on LIC aluminum imports. The difference arises because aluminum produced in low income countries is more carbon intensive. Even if the Annex-I countries do not pursue optimal policy and instead price embodied carbon at the domestic price (\$35 per ton), the implied aluminum tariffs are large at $15 \%$ ad valorem on imports from low income countries.

With the optimal unconstrained policy established, we now consider a comparison of embodied-carbon pricing on aluminum imports and the domestic carbon price when the objective is purely environmental. With the GATT constraint imposed, Figure 2 shows that the optimal trade distortion drops dramatically to $\$ 18$ per ton. This is roughly half of the domestic carbon price. In effect, following the standard prescription of imposing the domestic carbon price on embodied carbon imports indicates that about half of the trade distortion is a hidden beggar-thy-neighbour policy. At $\$ 18$ per ton of $\mathrm{CO}_{2}$, the ad valorem equivalent is a relatively modest $5 \%$ on MIC countries and $8 \%$ on LIC countries.

In our final set of simulations we consider the proposal of full border adjustments. This 


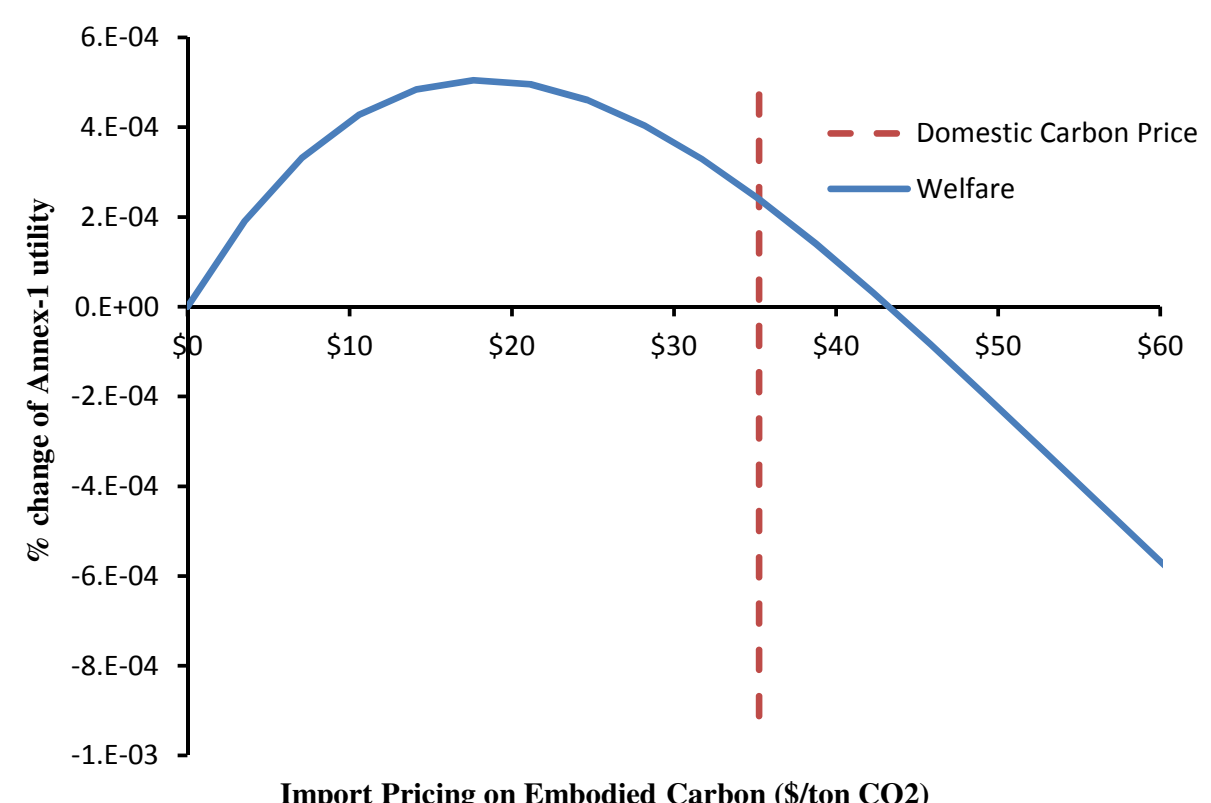

Figure 2: Aluminum Import Border Adjustment: GATT Constrained

policy advises that, in addition to imposing embodied-carbon tariffs, regulated countries would impose embodied-carbon subsidies on exports. That is, there would be a rebate of the accumulated value of carbon charges in the supply chain at the point of export. While these proposed policies appear in the literature and are often studied in numeric simulation, there is no clear theoretic justification for their adoption. Elliott et al. (2010) argue that in an open economy, full border adjustment effectively transforms a domestic production tax on carbon emissions into a consumption tax on embodied emissions. This could reduce leakage because developed countries are net importers of embodied emissions. Elliott et al. (2010) are careful, however, in not suggesting that full border adjustment is optimal. In addition, full border adjustment could run into legal problems, because its export rebate provision could be viewed as a per se violation of GATT rules on export subsidies. Cosbey et al. (2012) argue that export adjustments are not recommended because they clash with trade laws and their administration is otherwise problematic. Full border adjustments could generate overall cost savings, however, because part of the tariff-induced consumption response in unregulated 
Table 2: Optimal ad valorem Tariffs and Subsidies on Aluminum Under Full Border Adjustment

\begin{tabular}{lrrr}
\hline Region & Tariff & $\begin{array}{r}\text { Export } \\
\text { Subsidy }\end{array}$ & $\begin{array}{r}\text { Embodied } \\
\mathrm{CO}_{2} \text { Price }\end{array}$ \\
\hline MIC & $8.8 \%$ & $4.4 \%$ & $\$ 28.19$ \\
LIC & $12.1 \%$ & $4.4 \%$ & $\$ 28.19$ \\
\hline
\end{tabular}

regions is being displaced by subsidized goods produced under more efficient technologies.

In Figure 3 we plot Annex-I welfare as a function of the carbon price imposed on imports, as well as exports, of aluminum (full border adjustment). Two results are of note. First, optimal carbon pricing of trade is much closer to the domestic carbon price. The optimal pricing on embodied carbon in trade is $\$ 28$ per ton, which is about $80 \%$ of the domestic carbon price. As highlighted by Yonezawa et al. (2012), a version of Lerner's symmetry (Lerner, 1936) applies, in that import tariffs are offset by export subsidies. In this sense, a higher overall pricing of carbon on imports is optimal as long as there is a counteracting export subsidy. Second, comparing Figure 2 with Figure 3, optimal welfare in Annex-I is higher under full border adjustments relative to an import-only policy. This reflects the cost savings due to driving world aluminum consumption toward relatively low emissions intensive sources. Consider the implied ad valorem rates presented in Table 2, which simply reflect the embodied carbon coefficients calculated using the MRIO method. The key point is that aluminum from Annex-1 has a relatively lower carbon intensity, and thus Annex-1 can improve welfare through export subsidies which displace high carbon intensive aluminum in other countries.

\section{Conclusion}

In this paper, we consider optimal border adjustments in a setting with noncooperative environmental policy, but cooperative trade policy. Following Markusen (1975) we establish 


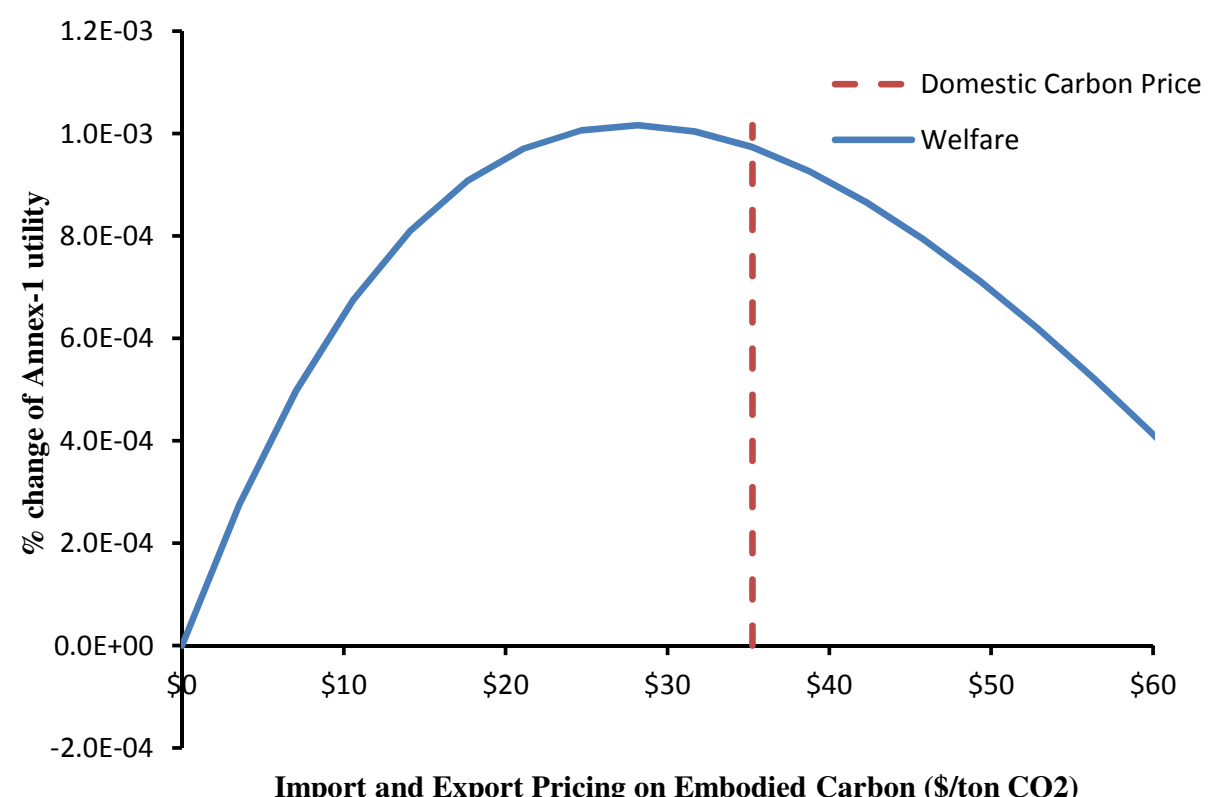

Figure 3: Aluminum Full Border Carbon Adjustment: GATT Constrained

optimal border policy in the presence of cross-border environmental damage. Because the optimal border policy includes a strategic component that is inconsistent with legal commitments under the General Agreement on Tariffs and Trade (GATT), we reevaluate optimal border policy that incorporates a GATT restriction reflecting cooperative trade. We show in this setting that the optimal border adjustment taxes the carbon content of trade at something different (and normally below) the domestic Pigouvian carbon price.

This finding is of first-order importance for policymakers, as it stands in contrast to the standard advise to impose the domestic carbon price on the carbon content of trade. The wedge between the domestic carbon price and the optimal border adjustment arises in general equilibrium because border adjustments inadvertently drive up consumption of emissionsintensive goods in unregulated regions. The magnitude of this wedge depends on the ability of the country imposing the tariffs to affect world prices and ultimately production of the polluting good in unregulated countries. If world price is unaffected by the trade policy of the regulating country, or if production in unregulated countries is unresponsive to changes 
in world price, the optimal border adjustment tends toward zero.

Our numerical simulations of Annex-I carbon policy illustrate this is not simply a theoretical concern. We find an optimal import tariff on the carbon content of aluminum that is on the order of $50 \%$ lower than the domestic carbon price. Countries that impose border carbon adjustments at the domestic carbon price will be extracting rents from unregulated regions at the expense of efficient environmental policy and consistency with international law.

\section{References}

Aldy, Joseph E., and Robert N. Stavins (2008) 'Designing the Post-Kyoto climate regime: Lessons from the Harvard project on international climate agreements.' Report, Harvard Kennedy School, Belfer Center for Science and International Affairs, November

Aldy, Joseph E., Peter R. Orszag, and Joseph E. Stiglitz (2001) 'Climate change: An agenda for global collective action.' Conference Paper, Pew Center on Global Climate Change, October

Allen, Derry (2010) 'OECD global forum on environment focusing on sustainable materials management: Materials case study 2: Aluminum.' OECD Working Document, OECD Environment Directorate

Barrett, Scott, and Robert Stavins (2003) 'Increasing participation and compliance in international climate change agreements.' International Environmental Agreements 3(4), 349376

Böhringer, Christoph, Andreas Lange, and Thomas F. Rutherford (2014) 'Optimal emission pricing in the presence of international spillovers: Decomposing leakage and terms-of-trade motives.' Journal of Public Economics 110(1), 101 - 111

Böhringer, Christoph, Jared C. Carbone, and Thomas F. Rutherford (2013a) 'Embodied carbon tariffs.' Working Papers, University of Calgary, August

_ (2013b) 'The strategic value of carbon tariffs.' Working Papers 4482, Center for Economic Studies and the Ifo Institute (CESifo), November

Bray, E. Lee (2010) '2008 minerals yearbook: Aluminum.' U.S. Geological Survey annual publication, U.S. Geological Survey

Carbone, Jared C., and V. Kerry Smith (2013) 'Valuing nature in a general equilibrium.' Journal of Environmental Economics and Management 66(1), 72 - 89 
Cosbey, Aaron, Susanne Droege, Carolyn Fischer, Julia Reinaud, John Stephenson, Lutz Weischer, and Peter Wooders (2012) 'A guide for the concerned: Guidance on the elaboration and implementation of border carbon adjustments.' Entwined Policy Report 03, Entwined

de Cendra, Javier (2006) 'Can emissions trading schemes be coupled with border tax adjustments? an analysis vis-à-vis WTO law.' Review of European Community \& International Environmental Law 15(2), 131-145

Elliott, Joshua, Ian Foster, Samuel Kortum, Todd Munson, Fernando Pérez Cervantes, and David Weisbach (2010) 'Trade and carbon taxes.' American Economic Review 100(2), 465 $-469$

GATT (1970) 'Working party report on border tax adjustments.' GATT Working Party Report, WTO

Hoel, Michael (1996) 'Should a carbon tax be differentiated across sectors?' Journal of Public Economics 59(1), 17 - 32

Horn, Henrik, and Petros C. Mavroidis (2011) 'To b(ta) or not to b(ta)? on the legality and desirability of border tax adjustments from a trade perspective.' The World Economy 34(11), 1911-1937

Lerner, Abba P. (1936) 'The symmetry between import and export taxes.' Economica $3(11), 306-313$

Markusen, James R. (1975) 'International externalities and optimal tax structures.' Journal of International Economics 5(1), 15 - 29

Narayanan, G. Badri, and Terrie L. Walmsley (2008) Global Trade, Assistance, and Production: The GTAP 7 Data Base (Center for Global Trade Analysis: Purdue University)

Pauwelyn, Joost (2013) 'Carbon leakage measures and border tax adjustments under WTO law.' In Research Handbook on Environment, Health and the WTO, ed. Geert Van Calster and Denise Prévost Research Handbooks on the WTO series (Cheltenham, UK: Edward Elgar Publishing, Inc.) chapter 15, pp. 448-506

Rutherford, Thomas F. (2010) 'Climate-linked tariffs: Practical issues.' In 'Thinking Ahead on International Trade (TAIT) Second Conference Climate Change, Trade and Competitiveness: Issues for the WTO'

Stiglitz, Joseph E. (2013) 'Sharing the burden of saving the planet: Global social justice for sustainable development.' In The Quest for Security: Protection without Protectionism and the Challenge of Global Governance, ed. Mary Kaldor and Joseph E. Stiglitz (New York: Columbia University Press) pp. 161-190 
Tamiotti, Ludivine (2011) 'The legal interface between carbon border measures and trade rules.' Climate Policy 11(5), 1202-1211

van Asselt, Harro, Thomas L. Brewer, and Michael A. Mehling (2009) 'Addressing leakage and competitiveness in US climate policy: Issues concerning border adjustment measures.' Working Papers, Climate Strategies

Vandendorpe, Adolf L. (1972) 'Optimal tax structures in a model with traded and non-traded goods.' Journal of International Economics 2(3), 235-256

Yonezawa, Hidemichi (2012) Theoretic and Empirical Issues Related to Border Carbon Adjustments (Ph.D. Thesis: Colorado School of Mines)

Yonezawa, Hidemichi, Edward J. Balistreri, and Daniel T. Kaffine (2012) 'The suboptimal nature of applying pigouvian rates as border adjustments.' Working Paper 2012-02, Colorado School of Mines: Division of Economics and Business

\section{A GATT Article XX: General Exceptions}

Subject to the requirement that such measures are not applied in a manner which would constitute a means of arbitrary or unjustifiable discrimination between countries where the same conditions prevail, or a disguised restriction on international trade, nothing in this Agreement shall be construed to prevent the adoption or enforcement by any contracting party of measures:

(a) necessary to protect public morals;

(b) necessary to protect human, animal or plant life or health;

(c) relating to the importations or exportations of gold or silver;

(d) necessary to secure compliance with laws or regulations which are not inconsistent with the provisions of this Agreement, including those relating to customs enforcement, the enforcement of monopolies operated under paragraph 4 of Article II and Article XVII, the protection of patents, trade marks and copyrights, and the prevention of deceptive practices; 
(e) relating to the products of prison labour;

(f) imposed for the protection of national treasures of artistic, historic or archaeological value;

(g) relating to the conservation of exhaustible natural resources if such measures are made effective in conjunction with restrictions on domestic production or consumption;

(h) undertaken in pursuance of obligations under any intergovernmental commodity agreement which conforms to criteria submitted to the CONTRACTING PARTIES and not disapproved by them or which is itself so submitted and not so disapproved;*

(i) involving restrictions on exports of domestic materials necessary to ensure essential quantities of such materials to a domestic processing industry during periods when the domestic price of such materials is held below the world price as part of a governmental stabilization plan; Provided that such restrictions shall not operate to increase the exports of or the protection afforded to such domestic industry, and shall not depart from the provisions of this Agreement relating to non-discrimination;

(j) essential to the acquisition or distribution of products in general or local short supply; Provided that any such measures shall be consistent with the principle that all contracting parties are entitled to an equitable share of the international supply of such products, and that any such measures, which are inconsistent with the other provisions of the Agreement shall be discontinued as soon as the conditions giving rise to them have ceased to exist. The CONTRACTING PARTIES shall review the need for this sub-paragraph not later than 30 June 1960. 


\section{B Proof of Theorem 1 (Markusen 1975)}

We derive one equation from (5) and two equations from (2), and we substitute those equations into the welfare change equations in the following pages. First, if a unique domestic import quantity is associated with every world price ratio, from the balance-of-payments constraint (5), we can specify the world price ratio as a function of the import quantity as follows:

$$
p^{*}=E\left(e_{X}\right)
$$

Second, as Vandendorpe (1972) derives from (2), the supply relationships are

$$
\frac{d X_{r}}{d p_{r}}=R_{X r}, \quad \text { where } \quad R_{X r}=\left(-\frac{\partial^{2} L_{r}}{\partial\left(X_{r}\right)^{2}}\right)^{-1}, \quad r \in\{N, S\}
$$

where $p_{N}=p$ and $p_{S}=p^{*}$. Third, totally differentiating (2) and dividing by $\frac{\partial F_{r}}{\partial Y_{r}}$ yields

$$
\frac{\partial F_{r} / \partial X_{r}}{\partial F_{r} / \partial Y_{r}} d X_{r}+d Y_{r}=p_{r} d X_{r}+d Y_{r}=0, \quad r \in\{N, S\}
$$

At an equilibrium, $\frac{\partial F_{r} / \partial X_{r}}{\partial F_{r} / \partial Y_{r}}$ equals $p_{r}$.

Totally differentiating (3) and dividing by $\frac{\partial U_{N}}{\partial C_{Y N}}$ yields the change in the North welfare in terms of consumption good $Y, \frac{d U_{N}}{\partial U_{N} / \partial C_{Y N}}$. Since the welfare in $N$ is maximized when $\frac{d U_{N}}{\partial U_{N} / \partial C_{Y N}}=0$, we find the conditions to make this true. The welfare change is as follows:

$$
\frac{d U_{N}}{\partial U_{N} / \partial C_{Y N}}=\frac{\partial U_{N} / \partial C_{X N}}{\partial U_{N} / \partial C_{Y N}} d C_{X N}+d C_{Y N}+\frac{\partial U_{N} / \partial Z}{\partial U_{N} / \partial C_{Y N}} d Z=q d C_{X N}+d C_{Y N}+q_{Z} d Z
$$

where, $q=\frac{\partial U_{N} / \partial C_{X N}}{\partial U_{N} / \partial C_{Y N}}$ is the marginal rate of substitution between goods $X$ and $Y$, and $q_{Z}=\frac{\partial U_{N} / \partial Z}{\partial U_{N} / \partial C_{Y N}}$ is the marginal rate of substitution between pollution $Z$ and good $Y$. $q_{Z}$ is negative because the pollution level $Z$ has a negative impact on the welfare $\left(\partial U_{N} / \partial Z\right.$ is negative). We make several substitutions to derive the optimal policy conditions. First, 
using $d C_{i N}=d i_{N}-d e_{i}$ from (5) yields

$$
\frac{d U_{N}}{\partial U_{N} / \partial C_{Y N}}=d Y_{N}-d e_{Y}+q d X_{N}-q d e_{X}+q_{Z} d Z
$$

Second, using $d e_{Y}=-e_{X} d p^{*}-p^{*} d e_{X}$ from (5) and $d Y_{N}=-p d X_{N}$ from (18) yields

$$
\frac{d U_{N}}{\partial U_{N} / \partial C_{Y N}}=e_{X} d p^{*}+\left(p^{*}-q\right) d e_{X}+(q-p) d X_{N}+q_{Z} d Z
$$

Differentiating (1) and replacing $d X_{S}$ by using (17) yields

$$
d Z=\frac{\partial Z}{\partial X_{N}} d X_{N}+\frac{\partial Z}{\partial X_{S}} R_{X S} d p^{*}
$$

Finally, by using $p^{*}-q=-q \tau$ and $q-p=q t_{X}$ from (4) and replacing $d Z$ from (22) and $d p^{*}$ from (16), (21) becomes

$$
\frac{d U_{N}}{\partial U_{N} / \partial C_{Y N}}=\left(e_{X} \frac{d p^{*}}{d e_{X}}+q_{Z} \frac{\partial Z}{\partial X_{S}} \frac{d X_{S}}{d p^{*}} \frac{d p^{*}}{d e_{X}}-q \tau\right) d e_{X}+\left(q t_{X}+q_{Z} \frac{\partial Z}{\partial X_{N}}\right) d X_{N} .
$$

Since the welfare change (or (23)) is zero at optimal, the optimal tariff and production tax are thus given by

$$
\begin{aligned}
\tau & =e_{X} \frac{\partial U_{N} / \partial C_{Y N}}{\partial U_{N} / \partial C_{X N}} \frac{d p^{*}}{d e_{X}}-\frac{\partial U_{N} / \partial Z}{\partial U_{N} / \partial C_{X N}} \frac{\partial Z}{\partial X_{S}} \frac{d X_{S}}{d p^{*}}\left(-\frac{d p^{*}}{d e_{X}}\right), \\
t_{X} & =-\frac{\partial U_{N} / \partial Z}{\partial U_{N} / \partial C_{X N}} \frac{\partial Z}{\partial X_{N}} .
\end{aligned}
$$




\section{Proof of Proposition 1}

We now modify the previous model to incorporate the transfer from the North to the South such that $U_{S}=\bar{U}_{S}$. Correspondingly, we modify (16) as follows:

$$
p^{*}=G\left(e_{X}, T\right), \quad d p^{*}=G_{X} d e_{X}+G_{T} d T .
$$

By using (25) and $d e_{Y}=d T-e_{X} d p^{*}-p^{*} d e_{X}$ derived from (8), (23) becomes:

$$
\begin{aligned}
\frac{d U_{N}}{\partial U_{N} / \partial C_{Y N}} & =\left(e_{X} \frac{\partial G}{\partial e_{X}}+q_{Z} \frac{\partial Z}{\partial X_{S}} \frac{d X_{S}}{d p^{*}} \frac{\partial G}{\partial e_{X}}-q \tau\right) d e_{X} \\
& +\left(q t_{X}+q_{Z} \frac{\partial Z}{\partial X_{N}}\right) d X_{N} \\
& +\left(e_{X} \frac{\partial G}{\partial T}+q_{Z} \frac{\partial Z}{\partial X_{S}} \frac{d X_{S}}{d p^{*}} \frac{\partial G}{\partial T}-1\right) d T
\end{aligned}
$$

Thus, we need to determine $d T$, or the change in the transfer required to hold the South's welfare constant. Assuming linear homogeneity of the utility functions, welfare of the South can be expressed as the ratio of income, denoted $I_{S}$, and the unit expenditure function, denoted as $c\left(p^{*}\right)$ :

$$
U_{S}=\frac{I_{S}}{c\left(p^{*}\right)}
$$

$I_{S}$ consists of the production value plus the transfer:

$$
I_{S}=p^{*} X_{S}+Y_{S}+T
$$

Combining the three equations (7), (27), and (28), we can derive

$$
T=\bar{U}_{S} c\left(p^{*}\right)-p^{*} X_{S}-Y_{S}
$$


Differentiating (29) and using (18) gives

$$
d T=\left(\bar{U}_{S} \frac{\partial c\left(p^{*}\right)}{\partial p^{*}}-X^{S}\right) d p^{*}
$$

Applying Shephard's lemma gives

$$
d T=e_{X} d p^{*}
$$

Replacing $d p^{*}$ by using (25) gives

$$
d T=\frac{e_{X} \frac{\partial G}{\partial e_{X}}}{1-e_{X} \frac{\partial G}{\partial T}} d e_{X}
$$

Substituting (32) into (26) yields

$$
\frac{d U_{N}}{\partial U_{N} / \partial C_{Y N}}=\left(-q_{Z} \frac{\partial Z}{\partial X_{S}} \frac{d X_{S}}{d p^{*}} \frac{-\frac{\partial G}{\partial e_{X}}}{1+\left(-e_{X}\right) \frac{\partial G}{\partial T}}-q \tau\right) d e_{X}+\left(q t_{X}+q_{Z} \frac{\partial Z}{\partial X_{N}}\right) d X_{N}
$$

Furthermore, we substitute $\frac{-\frac{\partial G}{\partial e_{X}}}{1+\left(-e_{X}\right) \frac{\partial G}{\partial T}}$ out as follows. From (25) we have

$$
\frac{d p^{*}}{d\left(-e_{X}\right)}=-\frac{d p^{*}}{d\left(e_{X}\right)}=-\frac{\partial G}{\partial e_{X}}-\frac{\partial G}{\partial T} \frac{d T}{d e_{X}} .
$$

Now from (32), (34) becomes

$$
\frac{d p^{*}}{d\left(-e_{X}\right)}=\frac{-\frac{\partial G}{\partial e_{X}}}{1+\left(-e_{X}\right) \frac{\partial G}{\partial T}}
$$

Thus, (33) becomes

$$
\frac{d U_{N}}{\partial U_{N} / \partial C_{Y N}}=\left(-q_{Z} \frac{\partial Z}{\partial X_{S}} \frac{d X_{S}}{d p^{*}} \frac{d p^{*}}{d\left(-e_{X}\right)}-q \tau\right) d e_{X}+\left(q t_{X}+q_{Z} \frac{\partial Z}{\partial X_{N}}\right) d X_{N} .
$$


Since the welfare change is zero at optimal, the optimal tariff and production tax are

$$
\begin{aligned}
\tau & =-\frac{\partial U_{N} / \partial Z}{\partial U_{N} / \partial C_{X N}} \frac{\partial Z}{\partial X_{S}} \frac{d X_{S}}{d p^{*}}\left(-\frac{d p^{*}}{d e_{X}}\right), \\
t_{X} & =-\frac{\partial U_{N} / \partial Z}{\partial U_{N} / \partial C_{X N}} \frac{\partial Z}{\partial X_{N}} .
\end{aligned}
$$

